\title{
A painful, never ending story: older women's experiences of living with an osteoporotic vertebral compression fracture
}

\author{
H. K. Svensson ${ }^{1,2}$ (1) • E. H. Olofsson ${ }^{1,2}$ • J. Karlsson ${ }^{3} \cdot$ T. Hansson $^{3}$ - L.-E. Olsson ${ }^{1,2}$
}

Received: 5 May 2015 / Accepted: 30 November 2015 / Published online: 11 December 2015

(C) The Author(s) 2015. This article is published with open access at Springerlink.com

\begin{abstract}
Summary Vertebral compression fractures (VCF) cause pain and decreased physical ability, with no known wellestablished treatment. The aim of this study was to illuminate the experience of living with a VCF. The results show that fear and concerns are a major part of daily life. The women's initial contact with health-care providers should focus on making them feel acknowledged by offering person-centered and tailored support.

Introduction In the past decade, osteoporotic-related fractures have become an increasingly common and costly public health problem worldwide. Vertebral compression fracture (VCF) is the second most common osteoporotic fracture, and patients with VCF describe an abrupt descent into disability, with a subsequent desire to regain independence in everyday life; however, little is known of their situation. The aim of this study was to illuminate the lived experience of women with an osteoporotic VCF.

Methods Ten women were interviewed during 2012-2013, starting with an open-ended question: could you tell me what it is like to live with a vertebral compression fracture? The verbatim transcribed interviews were analyzed using a phenomenological hermeneutical approach.
\end{abstract}

H. K. Svensson

hilda.svensson@gu.se

1 Institute of Health and Care Sciences, Sahlgrenska Academy, University of Gothenburg, PO Box 457, SE 405

30 Gothenburg, Sweden

2 Gothenburg Centre for Person-Centred Care (GPCC), University of Gothenburg, Gothenburg, Sweden

3 Sahlgrenska Academy, University of Gothenburg, Gothenburg, Sweden
Results The narrative provided descriptions of living in turmoil and chaos, unable to find stability in their life with little improvement regarding pain and physical function. Shifts from periods of constant pain to periods of fear of constant pain created a loss of confidence and an increased sense of confinement. The structural analysis revealed fear and concerns as the most prominent experience building on five themes: struggling to understand a deceiving body, breakthrough pain fueling fear, fearing a trajectory into isolation, concerns of dependency, and fearing an uncertain future.

Conclusions Until researchers find a successful prevention or medical/surgical treatment for osteoporotic VCFs, health-care providers and society abandon these women to remain in a painful and never ending story.

Keywords Elderly women · Experience · Nursing · Osteoporotic vertebral compression fracture $\cdot$ Person-centered care $\cdot$ Phenomenological hermeneutics $\cdot$ Transition

\section{Introduction}

During the past decades, osteoporosis has become an increasingly common and costly global public health problem [1]. In the great majority, it has an asymptomatic and progressively deteriorating disease trajectory and can be referred to as a silent disease, given that most individuals are unaware of the diagnosis until the first fracture occurs [2-4]. It leads to increased morbidity and mortality due to the high risk of fractures particularly of the hip, vertebrae, humerus, and distal radius [5-10].

Against the backdrop of demographic transformation and increased life expectancy, Sweden and other countries face a problem of growing number of older people suffering from osteoporosis, with the associated risk of fractures. This results 
in not only personal symptoms but also considerable economic burden [11]. A crucial public health issue is to prevent or postpone osteoporotic fractures, given that late-life activity limitation is one of the central components, among others, fueling increased costs [12].

Vertebral compression fracture (VCF) is one of the most common osteoporotic fractures [3]. Suzuki et al. [13] followed the natural course of acute VCFs in a Swedish cohort of women and men during the first year after the fracture, showing that fracture episode was the beginning of a long-lasting, severely painful, and disabling condition. Most patients reported high pain intensity and disability and impaired physical function in daily activities with reduced quality of life $[13,14]$. Studies from Sweden, Canada, and the USA show that despite these symptoms, approximately $75 \%$ of patients seeking emergency care do not receive any treatment plan. Instead, they are sent home with insufficient pain medication and without organized support or follow-up $[13,15,16]$. In a study of the experience of VCFs, constant pain, loss of independence and functional ability, changes in physical appearance, feelings of isolation, a sense of vulnerability, and an uncertain future were described as hallmarks of the experience [17]. A more recent study has shown that VCF negatively impacts the self-image and diminishes the self-confidence of those afflicted through loss of roles and bodily changes, under the threat of sustaining a new fracture [4]. Another study showed that women lean on their embodied self to interpret their everyday health and that everyday health is important in constructing their identity [18].

The onset of VCF is sudden, and daily life becomes a constant strive for independence [4]. A person with VCF can be seen as being thrown into a health-related transition from a stable familiar situation into instability, striving to reestablish a situation of stability [19]. When a person undergoes a health-related transition, professional support is of great importance to facilitate the transition process so that the trajectory is directed towards improved health [20]. Transitions related to VCF will leave the patient in a vulnerable situation that could, without support, lead to an unhealthy transition. Research has shown that trajectories towards a healthy transition can be supported through selfmanagement strategies to increase health-related quality of life and decrease the risk of dependence [19,21]. Evidence suggests that patients who sustain VCF do not receive the help and support that their condition requires [4, 14, 17, 22, 23]. Hansen et al. [3] describe the experience of being diagnosed with osteoporosis as a process of not being taken seriously by health-care providers, with the subsequent demand of becoming one's own health advocate. Despite the increasing incidence and prevalence of osteoporosis and VCFs in older adults, only few studies have described the lived experience $[3,4,7,17,23,24]$. Most studies focus on treatment effects, different experimental surgical procedures, and the probability of rehabilitative interventions [25-28].
There is a small body of existing literature on the subjective experience of living with osteoporotic VCF, as well as personal prerequisites to start a healthy transition. These studies argue that important questions remain unanswered regarding the lived experience of this condition in the context of transition. Therefore, the aim of this study was to illuminate the lived experience of women with osteoporosis-related VCF.

\section{Methods}

\section{Design}

The method used in this study aimed to describe daily life as experienced by women with a verified VCF, with the assumption that the reality is what they perceive it to be, i.e., emergent and multiple, where experiences and values are linked together. A qualitative method was used, developed by Lindseth \& Norberg 2004 [29], with a phenomenological hermeneutical approach inspired by Paul Ricoeur's philosophy of interpretation. A holistic life-world perspective underlies both phenomenology and hermeneutics but hermeneutics also describes an understanding that depends on interpretation, as opposed to the phenomenological method that strives to maintain objective. Phenomenological hermeneutics as a research method strives to gain insight about lived experience in people's daily life and to describe rather than to explain. The women's narratives were dependent on time and thereby it became a crucial factor, with a past, present, and future. Through the three dialectical levels of the analysis process, naïve understanding can be seen as an interpretive theoretical analysis which, in the dialect movement with the thematic structural analysis, created a comprehensive understanding that deepened, clarified, and strengthened the findings $[29,30]$.

\section{Participants}

All participants were identified through a purposeful selection at an outpatient clinic in Gothenburg, Sweden, during August to October 2012. The inclusion criteria were set at women aged $>65$ years, diagnosed with one or several osteoporotic VCFs with subsequent pain (visual analog scale score $\geq 5$ ) and reduced physical function. Possible participants with a recent injury and/or newly diagnosed were excluded because the study aimed to describe the process of living with chronic symptoms of the VCF and its influences on daily life. Potential participants were contacted by telephone by the first author, received written information, and gave their informed consent. A total of 17 women were contacted for participation, seven declined, two women declined based on lack of interest, and five women felt that they (in their current situation with fatigue and high levels of pain) could not manage undergoing an interview. The final sample of 10 women featured a variety 
of ages, vertebral fracture levels, physical capacity, and severity of complications subsequent to the fracture. The first author conducted all interviews with the women in their homes. The participants' average age was 80.1 years, and they lived in their own homes either alone or with a spouse or adult child. The women also represented a variety of socioeconomic conditions from well-situated to underprivileged (Table 1).

\section{Data collection}

Data were collected during an 8-month period from 2012 to 2013 through individual interviews starting with an open-ended question: Could you tell me what it is like to live with a vertebral compression fracture? The main purpose of the interviews was to allow the participant to narrate as freely as possible [29]. In order to create a trusting relationship with the informants, each interview began with a brief description of the first author's background as a district nurse with extensive experience of elder care. This was done because topics discussed could be regarded as personal and sensitive. This may have influenced the narrative content but was considered by the authors to be a possibility to create a sense of confidence and trust in the interview situation. By doing so, the women opened up and gave rich descriptions of their lived experience of the time after the fracture until the present time. During the interview, follow-up questions were asked to ensure a detailed and in-depth description of the experience on how the fracture had affected the various dimensions of their everyday lives, but also created an opportunity for the participant to reflect on their situation. Descriptions of the interview setting, emotions, gestures, and body language were captured in memos and field notes, which constituted a good complement in the analysis of the text. The interviews lasted between 50 and $75 \mathrm{~min}$ and were recorded and then transcribed verbatim by the first author to minimize the risk of differences between the oral and written discourse.

\section{Data analysis}

The transcribed interviews were analyzed using a phenomenological hermeneutical approach, and the process of interpretation was continued through a dialectic dialog between the naïve understanding and the structural analysis in order to formulate a comprehensive understanding [29].

First, to get a sense of the whole, all interviews were read in order to understand the uniqueness of the individual descriptions of the phenomena and to obtain an overall sense of the meaning of the women's experiences. In doing so, a naïve understanding was formulated.

Second, the interview text underwent a structural analysis starting with identifying meaning units. The meaning units were condensed, without losing the essential meaning, and compared to find similarities or differences in order to formulate sub-themes and themes.

Throughout the process of analysis, the dialectic movement between themes and naïve understanding was critically and theoretically reflected upon in order to deepen and validate the findings and to be able to formulate a comprehensive understanding [29].

\section{Trustworthiness}

The interviews and the analysis were guided by Lindseth and Norberg [29]. The method is based on the dialect movement through three methodological levels to deepen the meaning of the data and to facilitate awareness of pre-understanding throughout the whole research process, which strengthens the trustworthiness of the findings. The meaning units and the interpretation were continuously discussed by the first and last author throughout the analysis in terms of the relationship between the whole text, the naïve understanding, and the structural analysis, in order to strengthen the trustworthiness of the analysis. The naïve understanding of the text was formulated from the initial reading. The text was read again as a whole, the naïve understanding and the themes were
Table 1 Characteristics of the participants

\begin{tabular}{llllllll}
\hline $\begin{array}{l}\text { Participant's } \\
\text { ID }\end{array}$ & $\begin{array}{l}\text { Age } \\
\text { (years) }\end{array}$ & $\begin{array}{l}\text { Time since } \\
\text { VCF (years) }\end{array}$ & Housing & $\begin{array}{l}\text { Outdoor } \\
\text { access }\end{array}$ & $\begin{array}{l}\text { Marital } \\
\text { status }\end{array}$ & Children & $\begin{array}{l}\text { Home health- } \\
\text { care service }\end{array}$ \\
\hline 1. & 81 & 2 & Apartment & Stairs & Married & No & No \\
2. & 82 & 1 & House & Stairs & Widow & Yes & Yes \\
3. & 66 & 5 & Apartment & Elevator & Married & No & No \\
4. & 84 & 1.5 & House & Stairs & Widow & Yes & No \\
5. & 79 & 5 & Apartment & Elevator & Cohabiting & Yes & Yes \\
6. & 89 & 3 & House & Stairs & Widow & Yes & Yes \\
7. & 91 & 2 & Apartment & Stairs & Widow & Yes & Yes \\
8. & 65 & 3 & Apartment & Stairs & Single & Yes & No \\
9. & 85 & 2.5 & House & Stairs & Married & Yes & No \\
10. & 79 & 4 & Apartment & Elevator & Widow & Yes & Yes \\
\hline
\end{tabular}


reflected on in relation to the literature about the meaning of lived experience, and a comprehensive understanding was formulated [29]. Phenomenological hermeneutic analysis of research interviews requires high levels of interpersonal sensitivity, integrity, and reflexivity towards the interviewee but also towards one's pre-understanding of the phenomena [31]. The interviewers can only understand the narrative in relation to their pre-understanding, and there is a risk of misunderstanding. To check our understanding of the narratives or elements in the narrative, we checked with the interviewees during the interview using questions such as: What do you mean? Could you describe? [29]. In order to take a critical stance, informants were asked probing questions targeting different aspects of the pre-understanding of the authors. Throughout the analysis, the authors also broadened their awareness through critical discussions with peers and by studying relevant literature [29, 32, 33].

\section{Ethical considerations}

Ethics approval for the study was obtained from the regional ethics committee (dnr: 862-12). Participants who agreed to participate provided written informed consent and were guaranteed that they could at any time end their participation in the study and request termination of the tape recordings without any consequences. They were also informed of measures to ensure participant confidentiality, including not being identified by name on any recordings or later in the transcript or in any publication or presentation. An identification number was used to refer to the interview and recordings, and these study materials are kept locked at the University of Gothenburg.

\section{Findings}

\section{Naïve understanding}

The naïve understanding was based on the initial impression of the women's narrations regarding the experience of their situation and the meaning they expressed concerning their transition process.

The narratives provided descriptions of living in turmoil and chaos, unable to find stability in their life since the fracture. The informants describe their situation as shifting periods of constant intense pain replaced by fear of rapid onset of pain. Even if the pain was the main cause of their problematic situation, a sense of fear was the aspect that dominated the narratives. This fear led to an altered sense of self and changes in identity, leading to decreased confidence in their own ability, which forced them to adapt daily activities owing to reduced physical function and pain as a constant companion. A sense of loss of freedom and feeling of being confined increased the desire to be involved and needed and not to become marginalized and untrusted.

They felt betrayed by a changing and unpredictable body and described grief and anger over their body's frailty, which led to concerns of becoming a burden to themselves and others, risking that their significant others would get tired of taking care of them. They were not able to trust their bodies, which made them fearful and cautious in everyday activities, but they felt great satisfaction in managing to do what they could. They had a pronounced fear of falling and not being able to get up after lying down. Sometimes, they were so afraid of lying down in their beds that they preferred to sleep sitting up. They described a sense of helplessness and doubt facing a fragile body in an uncertain future, with memory and longing for what once was.

\section{Structural analysis}

The structural analysis of the interviews revealed fear and concerns as the most prominent experience. The VCF had thrown them into a new situation riddled with restraints and limitations, and their perception of their situation was similar regardless of the time elapsed since the initial VCF. During the interviews, the women came across as capable individuals, mostly through descriptions of the kind of individuals they once were before the fracture. They wanted to make sure that they were perceived as capable and willing individuals, but that they were simply left on their own in a difficult situation, not knowing what to do.

\section{Struggling to understand a deceiving body}

The women were aware of their bodily alteration in both function and appearance. They had gradually shrunk, developed a more stooped posture, and their belly had become more prominent. Functional limitations were caused through increased stiffness and physical fatigue, which made some of the women say that they could not manage to keep their back straight. It was not described as pain, but rather as a prostration in the back. These were all changes that many of the women had not noticed before the diagnosis of the VCF and were described as a bodily decay beyond their control.

Some of them felt they no longer trusted their bodies and as a result they had become more cautious in their movements and activities. They expressed a feeling of betrayal by their bodies that affected most aspects of everyday lives. Their life had become unstable, and they perceived their body as unpredictable and frail. They felt upset when they thought about activities they had enjoyed but no longer dared to do without extensive planning and foresight. To describe this, some of the women used the phrase "the head says yes, but the body says no." 


\section{Breakthrough pain fueling fear}

The initial pain was perceived as dreadfully intense and persistent, although it had changed in character over the years for all the women. For some, the pain had subsided in intensity and become more intermittent, while for others it had become constant and even. Regardless of intensity and frequency of the pain, the women described how they considered pain as a constant companion in their lives and that they just have to accept it.

Pain was a constant worry, either the women were experiencing severe pain or were afraid of severe breakthrough pain. Small movements that could induce sudden and strong stabbing pain could be movements of the arms, leaning forward, or just getting up from a lying position. The constant concern of doing involuntary or careless movements made them avoid unfamiliar and unpredictable situations. However, sometimes, despite the awareness of potential risks, they put their fear aside and went ahead and did something fully knowing that they would have to pay for it later.

They described the nights as especially troublesome, and sometimes they could not sleep through the whole night without waking up with severe pain. They tried to be careful how to position themselves in bed and many of them used sleeping pills to get some rest. For some of them, the bed triggered ambivalent feelings. Instead of being a place for relaxation it turned into a threatening trap that they might not be able to get up from, and this fear forced some of the women to sleep sitting upright in a chair.

They managed the breakthrough episodes of pain by balancing rest and simple activities. Many used analgesics, but had low confidence in their effectiveness. The drug effects were described as merely reducing the pain somewhat. Regardless of the intensity and frequency of the pain, the women described that they considered pain as a constant companion through life that they had become adapted to. The short moments when they were pain-free gave them a sense of being normal, but they always feared that the pain would recur and remind them of their injury when they performed any movements.

\section{Fearing a trajectory into isolation}

The women described feelings of boredom and loneliness due to social isolation, as previously common activities became an ordeal both for the women themselves but also for those around them. The constant presence of pain but also frustration of being unheard, not been taken seriously, and feeling restricted affected their mood, and the women knew that their bad mood was difficult to handle for relatives and friends.

They expressed a sense of entrapment and confinement in their homes, but also geographical limitation, due to fear, pain, and a sense of shame over their changing bodies. They talked about living day by day and that they had difficulties in planning their social life since a breakthrough pain could interfere with planned activities. They wanted to meet with friends but knew they could be forced to cancel with short notice. Hence, to reduce their sense of guilt for doing so, it was easier not to plan social activities and risk creating disappointment.

In the narratives, the experience of helplessness became obvious, which negatively influenced the women's self-confidence. It was clear that they all valued autonomy and independence as important, and one of the worst thoughts was to be forced to leave their own homes and become institutionalized. In order to find a way to improve their health and to avoid developing dependency, they tried to understand why and what had caused their condition. They often felt that they were not being taken seriously by health-care providers, who saw them as untrustworthy and constantly referred them elsewhere. Despite increasing pain and discomfort, they felt they never got a thorough examination and ultimately they ended up being sent home with pain medication and advice to rest; in effect, no specific treatment at all. The women felt they were marginalized just because they were older and female and that they ought to accept a certain level of infirmities as part of a normal aging process.

They felt distrusted and met with reluctance by health-care providers and were always given low priority. All the women had continually been asking for radiographic examination and referral to the orthopedic department for a correct diagnosis. When they finally received the diagnosis of VCF, they were told that there was nothing more to do in terms of the injury and that they should rest and give it time. This was perceived as unsatisfying and frustrating; they describe feelings of being belittled. They felt that the care professionals saw them as unnecessary care seekers, and they felt ashamed when they were told that other patients where in greater need of care. An uninterested and indifferent attitude from health-care providers created a sense in the patient of no longer being significant and of being seen as a liability to society; in other words, they were no longer worth investing in but instead they had become a burden to society.

Concerns of creating feelings of guilt in their close family made some of the women diminish their symptoms. They withdrew from social contexts, as they assumed the burden on the family members would become too great. The thought of becoming dependent and a burden to others was described as appalling; they were afraid that people would get tired of them if they became too demanding.

\section{Fearing an uncertain future}

Many of the women expressed that they did not see themselves as having a future, which forced them to live day by day. An uncertain future was attributed to both increasing age, but also the consequences in life because of the fracture. The 
realization that the future may involve living with pain as a constant companion made it difficult to look ahead and to make plans for the future.

Many described their situation as hopeless. The injury in the back along with other ailments, related to increasing age, had made them lose their spark, and they saw life as gray and dull; life was not enjoyable anymore when they were in pain. Fear of sustaining a new fracture or causing severe pain together with the feeling of fatigue, not only physical fatigue but also mental fatigue in facing their situation, created a sense of being without a future.

\section{Comprehensive understanding}

The VCF was perceived, by the women, as a disabling condition affecting all aspects of their life. There were similar descriptions from all participants', regardless of the number of years that they had lived with VCF. The comprehensive understanding was a description of a downward trajectory starting with mistrusting their bodies and an increasing fear related to unpredictable pain leading to increasing isolation and an uncertain future. Disabilities have been shown to be a dynamic process where transitions to a deteriorating function are more common than transitions to an improved health [14, 34]. The transition process is described as a movement through three stages: an initial change/event, a stage of instability and distress, and a stage of balance and acceptance with an identifiable end-point [19,35].

In a recent study, it was argued that the actualization of selfcare ability may facilitate healthy transitions. Successful selfcare involves having continuous contact with health-care providers, being aware of a healthy lifestyle, being physically and mentally active, maintaining social relations with family and friends, as well as being satisfied with life and being able to look forward [20]. The women's descriptions, in the present study, suggest that the response from health-care providers could be seen as counterproductive from the self-care point of view. The participants lacked sufficient knowledge of their condition but showed engagement and turned to health-care providers for help and support. Their encounters with healthcare providers were very discouraging, and the providers were seen as disinterested, which made the women feel diminished and belittled. They were forced to become their own health advocates in explaining their illness and its consequences to others who did not take them seriously. Health-care providers did not ask about their needs and did not meet their expectations regarding appropriate information or support. This finding is in agreement with other studies, which have shown that people with chronic illness, such as osteoporosis, are not asked about their needs or expectations for receiving the appropriate support or treatment, and this situation prevents a positive transition and reaching a stable end-point in the transition process $[11,36]$. Change in health creates a process of transition, and people in transition tend to be more vulnerable to risks that may affect their health perception [19]. The transitional process for people with VCF has not been studied before, and the narratives indicate that this is both complex and multidimensional.

\section{Discussion}

Our main finding was the feeling of pronounced fear and concern. The constant pain and the prominent fear of rapid onset of severe pain were equally difficult for the women to live with, and despite the time elapsed since the VCF, they still found their situation incomprehensible. These findings are similar to those shown two decades ago, in a study that concluded that the essential structure of the trajectory of VCF was an abrupt descent into illness, disability, and deformity, leading reduced ability to continue to be an independent person [17]. The fear of pain caused several problems for the participants and one was the reluctance to leave their home due to fear of falling. This is in concordance with a previous study in which they found an increased risk of isolation and social withdrawal in women living with osteoporosis. According to the authors, the reduced life space was a result of feeling safe and secure in their own homes, and with the increased caution, it created the decreased social interaction [24]. The participants in the present study described how they had to be careful when walking in unknown locations. They feared to fall, knowing that it would potentially worsen their initial injury or cause a new fracture, and the participants abstained from going out in most situations. Fear of worsening their condition has also shown to be a strong motivator to keep on being active and to follow prescribed medication [15]. A trustful interaction between elderly women and health-care providers could strengthen their concordance and the prospects to continue an active life [24].

The narratives describe feelings of helplessness that strongly influenced the women's self-confidence and self-image. Self-image has been found to relate to perceived health, and the results from a previous study showed that women depended on their embodied self to interpret their everyday health. In this study, the authors concluded that everyday health was important for the participant's construction of identity. It has also been shown that better mobility, using fewer supportive devices, and performing activities of daily living more independently were positively related to higher selfconfidence scores. They also found that low self-confidence was highly predictive of the depressive symptoms expressed by the older women [18].

The women's encounters with health-care providers were very disappointing, making them feel belittled and unimportant which is in agreement with other studies [36, 37]. It was shown that people with chronic illness are not asked about 
their needs and therefore their expectations on receiving the appropriate type of help are not sufficiently met [36]. If healthcare providers do not include the patient as a partner in the care, as proclaimed in person-centered care, it can become a hindrance to recovery and cause increased suffering [37]. There seems to be very little progress in the care of women with VCF in the last decades. However, because no effective medical or surgical treatments for VCF are currently available, the only known rehabilitation is strategies in self-care.

The women felt questioned and not taken seriously from their significant others and constantly had to explain their illness perception and its consequences in daily life, which is in agreement with the previous findings [3]. Being repeatedly distrusted made the women reluctant to talk about their situation, which led to feelings of loneliness.

Overall, there is a lack of research in the experience of living with VCF caused by osteoporosis. Hopefully, our results, sometimes in concordance with previous studies, will highlight the necessity of further research on personal experiences, management, and the consequences of living with VCF in daily life.

\section{Limitations}

It may sometimes be difficult to inspire participants to narrate freely about their mundane daily life situation. However, people often like to talk about matters that are important to them. The number of informants in the study was small. However, their willingness to narrate and their detailed descriptions of their situation provided rich data, which compensated for the low number of study participants. The small number of rich interviews is also in line with the phenomenological hermeneutic method, aiming to gain a deeper insight into each of the women's stories rather than a general and superficial understanding.

Our study included only community-dwelling women, which can be seen as a limitation because it excluded a large group of frail older adults living in special housing. In order to address this limitation, we conducted a strategic purposeful sampling, i.e., age, social situation, time since initial injury, socioeconomic situation and context, to capture diversity in experiences and develop a valid description of living with VCF.

\section{Summary}

Living with a VCF means living with fear and concerns. Women with VCF are unable to find stability in life and experience little improvement in health in the years following the fracture. They endure periods of constant pain followed by periods of fear of rapid onset of pain, which leads to a loss of self-confidence and an increased sense of confinement. In contacts with health-care providers, the women felt belittled and unimportant, instead of being acknowledged and offered person-centered and tailored support. Until now, there are no successful medical or surgical treatments for VCF, and healthcare providers are ill-equipped to meet the needs of these women, abandoning them to remain in a painful and never ending story of instability and uncertainty. By creating supportive and person-centered functions within primary healthcare, providers can help these women to establish an increased sense of security, strengthen their beliefs in their own ability, and improve their self-confidence. Further research is needed to demonstrate the effects of person-centered interventions aiming to facilitate positive transition, i.e., the possibility of reaching a phase of stability and acceptance.

Acknowledgments This study was supported by the Centre for PersonCentred Care (GPCC) at the University of Gothenburg, Sweden. GPCC is funded by the Swedish Government's grant for Strategic Research Areas, Care Sciences [2009-1088]. This work was also supported by the Health and Medical Care Committee of the Regional Executive Board, Region Västra Götaland and the Institute of Health and Care Sciences at the University of Gothenburg, Sweden. We would also like to thank all the women participating, for telling us their stories and making this study possible.

Compliance with ethical standards Ethics approval for the study was obtained from the regional ethics committee (dnr: 862-12). Participants who agreed to participate provided written informed consent.

Conflicts of interest Funding sources had no involvement in the design, methods, subject recruitment, data collection, analysis and preparation of this manuscript or the decision to submit for publication. The corresponding author interviewed all the women, transcribing data and was finally responsible for submission for publication. All authors meet the criteria for authorship stated in the Uniform Requirements for Manuscripts Submitted to Biomedical Journals. Hilda Svensson, Elisabeth Hansson Olofsson, Jon Karlsson, Tommy Hansson and Lars-Eric Olsson declare that they have no conflict of interest or financial ties to disclose.

Open Access This article is distributed under the terms of the Creative Commons Attribution-NonCommercial 4.0 International License (http:// creativecommons.org/licenses/by-nc/4.0/), which permits any noncommercial use, distribution, and reproduction in any medium, provided you give appropriate credit to the original author(s) and the source, provide a link to the Creative Commons license, and indicate if changes were made.

\section{References}

1. National Osteoporosis Foundation (2015) 54 Million americans affected by osteoporosis and low bone mass. http://nof.org/news/ 2948. 2015-07-13. Accessed 13 July

2. Hagenfeldt $\mathrm{K}$, Alton V, Eksell S, Johansson C, Johnell O, Ljunggren Ö, Marké LÅ (2003) Osteoporosis - prevention, diagnosis and treatment. The Swedish Council on Technology Assessment in Health Care. ISBN 91-87890-86-0

3. Hansen C, Konradsen H, Abrahamsen B, Pedersen BD (2014) Women's experiences of their osteoporosis diagnosis at the time of diagnosis and 6 months later: A phenomenological hermeneutic study. Int J Qualitative Stud Health Well-Being 9:22438. doi:10. 3402/qhw.v9.22438 
4. Hallberg I, Ek AC, Toss G, Bachrach-Lindström M (2010) A striving for independence: a qualitative study of women living with vertebral fracture. BMC Nurs 9(1) http://www.biomedcentral. com/1472-6955/9/7

5. WHO Scientific Group on the Burden of Musculoskeletal Conditions at the Start of the New Millennium (2003) The burden of musculoskeletal conditions at the start of the new millennium. WHO Technical Report, vol 919. WHO, Geneva

6. Landis DM (2005) Fracture risk in postmenopausal women. Nurse Pract 30(11):48-58

7. Nielsen D, Huniche L, Brixen K, Sahota O, Masud T (2013) Handling knowledge on osteoporosis - a qualitative study. Scand J Caring Sci 27(3):516-524

8. National Osteoporosis Foundation (2015) What is osteoporosis? http://nof.org/articles/7. Accessed 13 July 2015.

9. Jalava T, Sarna S, Pylkkänen L, Mawer B, Kanis JA, Selby P, Davies M, Adams J, Francis MR, Robinson J, McCloskey E (2003) Association between vertebral fracture and increased mortality in osteoporotic patients. J Bone Miner Res 18(7):1254-1260

10. Kanis JA, Johansson H, Oden A, McCloskey EV (2009) Assessment of fracture risk. Eur J Radiol 71(3):392-397

11. Jahelka B, Dorner T, Terkula R, Quittan M, Bröll H, Erlacher L (2009) Health-related quality of life in patients with osteopenia or osteoporosis with and without fractures in a geriatric rehabilitation department. Wien Med Wochenschr 159(9-10):235-240

12. van Houwelingen AH, Cameron ID, Gussekloo J, Putter H, Kurrle S, de Craen AJM, Maier AB, den Elzen WPJ, Blom JW (2014) Disability transitions in the oldest old in the general populationThe Leiden 85-plus study. Age 36(1):483-493

13. Suzuki N, Ogikubo O, Hansson T (2008) The course of the acute vertebral body fragility fracture: its effect on pain, disability and quality of life during 12 months. Eur Spine J 17(10):1380-1390

14. Lips P, van Schoor NM (2005) Quality of life in patients with osteoporosis. Osteoporos Int 16(5):447-455

15. Beaton DE, Sujic R, Beaton KM, Sale J, Elliot-Gibson V, Bogoch ER (2012) Patient perceptions of the path to osteoporosis care following a fragility fracture. Qual Health Res 22:1647-1658

16. Freedman BA, Potter BK, Nesti LJ, Giuliani JR, Hampton C, Kuklo TR (2008) Osteoporosis and vertebral compression fractures - continued missed opportunities. Spine J 8(5):756-762

17. Paier GS (1996) Specter of the crone: the experience of vertebral fracture. Adv Nurs Sci 18(3):27-36

18. Roberto KA, McCann BR (2011) Everyday health and identity management among older women with chronic health conditions. J Aging Stud 25(2):94-100

19. Meleis AI (2010) Transitions theory: middle-range and situationspecific theories in nursing research and practice. Springer publishing company, New York

20. Söderhamn O (2013) Phenomenological perspectives on self-care in aging. Clin Interv Aging 2013(8):605-608

21. Olsson LE, Nyström AE, Karlsson J, Ekman I (2007) Admitted with a hip fracture: patient perceptions of rehabilitation. J Clin Nurs 16(5):853-859

22. Papaioannou A, Kennedy CC, Ioannidis G, Brown JP, Pathak A, Hanley DA, Josse RG, Sebaldt RJ, Olszynski WP, Tenenhouse A,
Murray TM, Petrie A, Goldsmith CH, Adachi JD (2006) Determinants of health-related quality of life in women with vertebral fractures. Osteoporos Int 17(3):355-363

23. Yoon SP, Lee SH, Ki CH, Lee YT, Hong SH, Lee HM, Moon SH (2014) Quality of life in patients with osteoporotic vertebral fractures. Asian Spine J 8(5):653-658

24. Berlin Hallrup L, Albertsson D, Bengtsson Tops A, Dahlberg K, Grahn B (2009) Elderly women's experiences of living with fall risk in a fragile body: a reflective lifeworld approach. Health Soc Care Community 17(4):379-387

25. Burke TN, França FJR, de Meneses SRF, Pereira RMR, Marques AP (2012) Postural control in elderly women with osteoporosis: comparison of balance, strengthening and stretching exercises-A randomized controlled trial. Clin Rehabil 26(11):1021-1031

26. Qvist N, Bergström I, Kronhed ACG, Karlsson S, Forss A (2011) Empowering the fragile body: experiences of a back muscle group training program in postmenopausal women with vertebral fractures. A qualitative interview study. Adv Physiother 13(2):63-70

27. Blasco J, Martinez-Ferrer A, Macho J, San Roman L, Pomés J, Carrasco J, Monegal A, Guañabens N, Peris P (2012) Effect of vertebroplasty on pain relief, quality of life, and the incidence of new vertebral fractures: a 12-month randomized follow-up, controlled trial. J Bone Miner Res 27(5):1159-1166

28. Schröder G, Knauerhase A, Kundt G, Schober HC (2012) Effects of physical therapy on quality of life in osteoporosis patients - a randomized clinical trial. Health Qual Life Outcomes 10(1):101

29. Lindseth A, Norberg A (2004) A phenomenological hermeneutical method for researching lived experience. Scand J Caring Sci 18(2): $145-153$

30. Fagerberg I, Norberg A (2009) Learning by doing — or how to reach an understanding of the research method phenomenological hermeneutics. Nurse Educ Today 29(7):735-739

31. Ellingsen S, Drageset S, McSherry W (2015) The interconnectedness of ethical, phenomenological and hermeneutical dimensions influencing trustworthiness in the qualitative research interview. Nordisk Sygeplejeforskning 1(5):70-78

32. Polit DF, Hungler PB (1999) Nursing research—principles and methods, Chapter 17. Lippincott Williams \& Wilkins, Philadelphia US

33. Lincoln YS, Guba EG (1985) Naturalistic Inquiry. Chapter 12. Sage Publications Inc, Canada

34. Ebrahimi Z, Wilhelmson K, Eklund K, Moore CD, Jakobsson A (2013) Health despite frailty: exploring influences on frail older adults' experiences of health. Geriatr Nurs 34(4):289-294

35. Meleis AI, Sawyer LM, Im EO, Messias DKH, Schumacher K (2000) Experiencing transitions: an emerging middle-range theory. Adv Nurs Sci 23(1):12-28

36. Olsson M, Skär L, Söderberg S (2011) Meanings of being received and met by others as experienced by women with MS. Int J Qualitative Stud Health Well-being 6:5769. doi:10.3402/qhw. v6i1.576

37. Sundin K, Axelsson K, Jansson L, Norberg A (2000) Suffering from care as expressed in the narratives of former patients in somatic wards. Scand J Caring Sci 14(1):16-22 